\title{
DFT study on deprotonation and protonation of porphyrins: How many protons can the
}

\section{porphyrin core take up?}

Yao-Bing Yin

School of science, Hebei University of Engineering, Handan City, Hebei Province, 056038,

China

To whom correspondence should be addressed. Phone: +86 310 8578760. Fax: +86 3106025698 .

E-mail address: yaobingyin85@ sina.com (Yin Y-B)

\begin{abstract}
Deprotonation and protonation are crucial characteristics of porphyrins and porphyrinoids solutions. This report is indicated to investigate all possible deprotonated and protonated species of the porphine ring using DFT. In particular, based on the analysis of the optimized geometries and electronic structures of protonated species, it was confirmed theoretically that aromaticity and stability of the triacid or the tetraacid resulted from further protonation of the porphyrin diacid. Additional hydrogen atoms attached to the inner nitrogen atoms of protonated porphyrins and gave rise to rearrangement of aromatic system involving $\alpha-, \beta-$, and meso-carbons. Crowding inner hydrogen atoms attached to the pyrrole nitrogen atoms lead to distortion of porphyrin core. Substituents of porphyrins rendered it to be possible that the final species of the protonation process might be triacid or tetraacid.
\end{abstract}

Key words: deprotonation; protonation; density function theory; triacid; tetraacid. 


\section{Introduction}

As is well known, two natural chemicals, heme and chlorophyll, which involve the photosynthesis reaction and a variety of biologically vital processes, contain a porphine ring. Consequently, porphyrins and its miscellaneous derivatives have been continuously attracting research interests from multidisciplinary fields, including light harvesting, electron transfer, host-guest chemistry, photodynamic therapy, and design of biological sensors and imaging agents. [1,2] Protonation of macrocycles composed of porphine ring, which is an important phenomena in aqueous solution, influences substantially their structures, configurations, molecular environments, properties and applications.[3] Unfortunately, deprotonation and protonation of porphyrins, involving the interior pyrrole nitrogens bonding to hydrogen, remain some aspects to be realized and manifested explicitly.

Deprotonation means that one or two protons are abstracted from interior pyrrole nitrogen atoms while protonation implies that the interior pyrrole nitrogen atoms take up additional protons. Since the neutral free base of porphyrins has two hydrogen atoms oppositely bonding to two of four interior pyrrole nitrogen atoms in the porphine ring, two hydrogen atoms can be deprotonated sequentially, which is confirmed, as verified by Shaojun Dong et al [4], by deprotonation of meso-(p-hydroxyphenyl)porphyrins in $\mathrm{DMF}+\mathrm{H}_{2} \mathrm{O}(\mathrm{V} / \mathrm{V}=1: 1)$ mixture by different concentrated $\mathrm{NaOH}$ solution resulting in the appearance of hyperporphyrin spectra.

It is reasonably called monoprotonation or diprotonation that other two imine nitrogen atoms of the porphine ring bond to one or two protons with formation of mono- and di-cations respectively. A neutral water-soluble porphyrin $(\mathrm{TCHpH})$ is protonated in two distinct steps, which is rationalized by a model relating structural changes on the porphyrin macrocycle upon protonation to its basicity [5]. The model is validated by density functional theory (DFT) calculations performed on a planar and non-planar porphyrin. A monoprotonated species of porphyrins has been characterized as having three absorptions in the Q-band region.[6,7] The crystal structures of the octaethylporphyrin and dodecaphenylporphyrin monocations have also been presented. [8,9] Recently, spectrophotometric titrations for a full series of 
para-amino/carbomethoxy/pyridyl-substituted tetraphenylporphyrins provide evidences for a monoprotonated porphyrin, the relative stability of which is proposed to be due to charge delocalization of the first cation and destabilization of the second protonation by the electron-withdrawing substituents. [10,11]

In contrast to monoprotonation of porphyrin and its analogues, diprotonation species of porphyrins is well known which is formed as porphyrin diacid in acidic solutions by the free base porphyrin combining with two additional hydrogen atoms on the central nitrogen atom [12,13]. Porphyrin diacids were found to exhibit perturbed photophysical properties compared to their neutral parent compounds, including the substantially lowered quantum yield of triplet-state formation, altered electronic absorption spectra, increased Stokes-shifts in fluorescence spectra [14-19].

In an attempt to grasp the nature of the protonation of macrocycles, DFT calculations have been employed which have been quite successfully applied to study diverse aspects of porphyrin compounds including molecular geometries, electronic structures, vibrational spectra, etc. [20-24]. The ground-state structure, electronic spectrum and conformational inversion of porphyrin diacid, including OEP (octaethylporphyrin), TPP(meso-tetraphenylporphyrin), TPyP (meso-tetrapyridylporphyrin), OETPP (octaethyltetraphenylporphyrin), and TCHP (tetracyclohexaporphyrin), have been studied with the density functional theory, which resulted in the most stable structure of porphyrin diacid bearing a saddle-distorted porphyrin ring along with the structures of transition states and intermediates as well as the inversion barriers. [25] Using DFT calculations along with UV-vis and magnetic circular dichrosim spectroscopies, N-confused porphyrin (NCP) and its externally methylated variant were investigated, and then the sites of protonation/deprotonation for tautomeric forms of NCP were determined. [26] Recently, the investigation of the acid-base properties of a series of meso-aryl-substituted N-confused porphyrins (NCPs) in aqueous sodium dodecyl sulfate (SDS) micellar solutions using both spectrophotometric methods and theoretical calculations demonstrated that NCPs are easily protonated and deprotonated compared to the corresponding regular congeners. [27]

However, in these studies, there are at least two fundamental questions, whether the porphyrin 
diacid further bond other hydrogen atoms and which protonation step is energetically beneficial, are not extensively explored, which render us the opportunity to investigate them. It is known that the interior pyrrole nitrogens of the free base of porphyrins can be deprotonated or protonated to afford four possible derivatives, named herein as dianionic-, monoanionic-, monocationic- and dicationic species respectively, with moderately to strongly distorted core conformations $[28,29]$. In general, further protonation of pyrrole nitrogen is not considered because protonation of pyrrole, as is well known, results in loss of aromaticity of the five-membered heterocycle and is therefore unfavorable. Even though protonation does not occur at nitrogen, however, it does occur at carbon and the protonated pyrrole then adds another molecule like this [30]. Taking into account four pyrrole cycles existed in the porphyrin core and differences of conjugation system of porphyrins from that of annulene, the protonation of protonated pyrrole nitrogen can be possible to some extent. In this case, tricationic and tetracationic species will be afforded when one or two protonated pyrrole nitrogen atom is protonated.

In this report, we present the DFT study of all possible deprotonated and protonated species of several porphyrins (Scheme 1). Based on the analysis of the optimized geometries and electronic structures of deprotonated and protonated species, we confirm their aromaticity and stability. In particular, we have carried out the theoretical calculations of the formation Gibbs free energies of these molecules and then evaluate the energetically beneficial step of protonation. Furthermore, we shall take into consideration of effects of meso-substituents of porphyrins on their protonation processes.

Scheme 1. All possible protonated and deprotonated forms of the porphyrins.

\section{Computational methods}

DFT calculations were performed with the Gaussian 09 program package [31] with symmetry treatment. The geometries were fully optimized using Becke's three-parameter hybrid functional combined with the Lee-Yang-Parr correlation functional, denoted as the B3LYP level of density functional theory $[32,33]$, with the $6-31 \mathrm{G}(\mathrm{d}, \mathrm{p})$ or $6-31+\mathrm{G}(\mathrm{d}, \mathrm{p})$ basis sets $[34,27]$ as noted for all calculations.[35] For all optimized structures, the frequency calculation was carried out to verify 
the stable configuration of each species and to obtain the zero-point energy (ZPE) and the thermal energy contributions at $298.15 \mathrm{~K}$ and $1 \mathrm{~atm}$. By comparison, the singlet ground state structure of porphyrin species including implicit water was optimized under a self-consistent reaction field approach (SCRF) based on the application of the model IEFPCM to build a continuum of uniform dielectric constant simulating the solvation of water.

In cases of triacid and tetraacid species, geometry optimizations corrected with dispersion interaction were conducted additionally at the same level of theory as standard geometry optimizations and single point calculations.[36] In order to exhibit improved numerical stability and to better describe the electron distribution in porphine rings of high ionic character, natural population analyses were performed.[37]

\section{Results and Discussion}

\subsection{Optimized geometries}

In order to focus on the issue of deprotonation and protonation of porphyrin core and avoid complicated affects of substituents bounded to the porphine ring, salvation of solvents, concentrations of relevant species and possible hyperporphyrin effects, it is necessary to design a simple model structure. Taking the porphine ring as a model molecule, there are seven deprotonated and protonated porphine species including the free base of porphine, two anionic species, two commonly cationic products and two imaginary protonated porphines, termed herein as PP, $\mathrm{HPP}, \mathrm{H}_{2} \mathrm{PP}, \mathrm{H}_{3} \mathrm{PP}, \mathrm{H}_{4} \mathrm{PP}, \mathrm{H}_{5} \mathrm{PP}$ and $\mathrm{H}_{6} \mathrm{PP}$, respectively, depending on the hydrogen atoms bounded to the interior pyrrole nitrogen atoms. All other five possible species, except for PP and HPP, has more than one isomer involving the displacement of the interior hydrogen atoms. HPP has only one pattern for the interior nitrogen to bound a hydrogen atom, while PP dianion has another possible isomer of annulene with an additional $\mathrm{C}=\mathrm{C}$ bond (Scheme 1, PP'). The energetically beneficial isomers of $\mathrm{H}_{2} \mathrm{PP}, \mathrm{H}_{3} \mathrm{PP}, \mathrm{H}_{4} \mathrm{PP}$ have been suggested by crystallography data of some porphyrin crystals, which can be employed reasonably. For example, the crystal structures of diacids of OEP, TPP and TMP (5,10,15,20-tetramesitylporphyrin) have a distinct $\mathrm{D}_{2 \mathrm{~d}}$-saddled porphyrin core with four pyrrole NH protons alternately displacing above and below the 24-atom mean plane. [38] As for the energetically beneficial isomers of $\mathrm{H}_{5} \mathrm{PP}$ and $\mathrm{H}_{6} \mathrm{PP}$, our primary calculations implied an additional hydrogen bounding to one of the four pyrrole nitrogen for $\mathrm{H}_{5} \mathrm{PP}$, and two protons additionally connecting to two opposite interior nitrogen atoms in an alternately 
above and below pattern (Figure 1). Therefore, we carried out calculations of these eight stable conformations using density functions theory in B3LYP/6-31G(d,p) level and obtained their optimized structures (Figure 1). Table 1 and Table 2 list the optimized geometries parameters of these seven species at different basis sets level.

Figure 1. Optimized geometries $(\AA$, deg) of protonated and deprotonated porphine species. Hydrogen atoms out of the ring are omitted.

Table 1. Selected structural parameters of optimized geometries of PP, HPP, $\mathrm{H}_{2} \mathrm{PP}, \mathrm{H}_{3} \mathrm{PP}$, and $\mathrm{H}_{4} \mathrm{PP}$ by B3LYP/6-31G(d,p) calculations.

\begin{tabular}{|c|c|c|c|c|c|}
\hline & PP & HPP & $\mathrm{H}_{2} \mathrm{PP}$ & $\mathrm{H}_{3} \mathrm{PP}$ & $\mathrm{H}_{4} \mathrm{PP}$ \\
\hline \multicolumn{6}{|c|}{ Bond distances $(\AA)$} \\
\hline $\mathrm{C}_{\beta}-\mathrm{C}_{\beta}$ & 1.364 & 1.360 & 1.356 & 1.375 & 1.371 \\
\hline $\mathrm{C}_{\alpha}-\mathrm{C}_{\beta}$ & 1.470 & 1.464 & 1.460 & 1.426 & 1.436 \\
\hline $\mathrm{C}_{\alpha}-\mathrm{N}$ & 1.361 & 1.363 & 1.372 & 1.394 & 1.378 \\
\hline $\mathrm{C}_{\alpha}-\mathrm{C}_{\mathrm{m}}$ & 1.404 & 1.436 & 1.394 & 1.393 & 1.398 \\
\hline $\mathrm{C}_{\beta}-\mathrm{H}_{\beta}$ & 1.088 & 1.084 & 1.081 & 1.081 & 1.081 \\
\hline $\mathrm{C}_{\mathrm{m}}-\mathrm{H}_{\mathrm{m}}$ & 1.093 & 1.087 & 1.086 & 1.085 & 1.085 \\
\hline $\mathrm{N}-\mathrm{H}_{\mathrm{N}}$ & - & 1.024 & 1.014 & 1.012 & 1.017 \\
\hline \multicolumn{6}{|c|}{ Bond angles (deg.) } \\
\hline $\mathrm{C}_{\alpha}-\mathrm{C}_{\mathrm{m}}-\mathrm{C}_{\alpha}$ & 129.3 & 127.5 & 121.1 & 128.0 & 128.2 \\
\hline $\mathrm{C}_{\alpha}-\mathrm{N}-\mathrm{C}_{\alpha}$ & 106.9 & 109.9 & 110.8 & 110.5 & 108.0 \\
\hline $\mathrm{C}_{\alpha}-\mathrm{C}_{\beta}-\mathrm{C}_{\beta}$ & 106.3 & 105.8 & 108.0 & 108.3 & 108.2 \\
\hline $\mathrm{N}-\mathrm{C}_{\alpha}-\mathrm{C}_{\beta}$ & 110.6 & 107.4 & 106.6 & 106.8 & 106.4 \\
\hline $\mathrm{N}-\mathrm{C}_{\alpha}-\mathrm{C}_{\mathrm{m}}$ & 125.0 & 126.0 & 125.5 & 125.5 & 125.9 \\
\hline $\mathrm{C}_{\beta}-\mathrm{C}_{\beta}-\mathrm{H}_{\beta}$ & 127.6 & 107.6 & 127.7 & 127.2 & 124.5 \\
\hline $\mathrm{C}_{\alpha}-\mathrm{C}_{\mathrm{m}}-\mathrm{H}_{\mathrm{m}}$ & 115.3 & 114.8 & 115.9 & 116.1 & 115.9 \\
\hline $\mathrm{C}_{\alpha}-\mathrm{N}-\mathrm{H}_{\mathrm{N}}$ & - & 125.0 & 124.6 & 129.0 & 116.6 \\
\hline
\end{tabular}




$\begin{array}{llllll}\mathrm{N}-\mathrm{C}_{\alpha}-\mathrm{C}_{\beta}-\mathrm{H}_{\beta} & 180.0 & 180.0 & 180.0 & 176.5 & 180.0 \\ \mathrm{C}_{\mathrm{m}}-\mathrm{C}_{\alpha}-\mathrm{C}_{\beta}-\mathrm{C}_{\beta} & 180.0 & 180.0 & 180.0 & 178.1 & 177.6 \\ \mathrm{C}_{\alpha}-\mathrm{C}_{\beta}-\mathrm{C}_{\beta}-\mathrm{C}_{\alpha} & 0.0 & 0.0 & 0.0 & 0.0 & 0.3 \\ \mathrm{~N}-\mathrm{C}_{\alpha}-\mathrm{C}_{\beta}-\mathrm{C}_{\beta} & 0.0 & 0.0 & 0.0 & 0.9 & 0.3 \\ \mathrm{H}_{\mathrm{N}}-\mathrm{N}-\mathrm{C}_{\alpha}-\mathrm{C}_{\mathrm{m}} & - & 0.0 & 0.0 & 34.2 & 51.2 \\ \mathrm{H}_{\mathrm{N}}-\mathrm{N}-\mathrm{C}_{\alpha}-\mathrm{C}_{\beta} & - & 180.0 & 180.0 & 148.5 & 134.0 \\ \mathrm{~N}-\mathrm{C}_{\alpha}-\mathrm{C}_{\mathrm{m}}-\mathrm{H}_{\mathrm{m}} & 180.0 & 180.0 & 180.0 & 173.8 & 173.9 \\ \mathrm{~N}-\mathrm{C}_{\alpha}-\mathrm{C}_{\mathrm{m}}-\mathrm{C}_{\alpha} & 0.0 & 0.0 & 0.0 & 8.4 & 1.3 \\ \mathrm{C}_{\alpha}-\mathrm{C}_{\mathrm{m}}-\mathrm{C}_{\alpha}-\mathrm{C}_{\beta} & 180.0 & 180.0 & 180.0 & 177.1 & 178.1 \\ \mathrm{H}_{\mathrm{m}}-\mathrm{C}_{\mathrm{m}}-\mathrm{C}_{\alpha}-\mathrm{C}_{\beta} & 0.0 & 0.0 & 0.0 & 5.1 & 2.9 \\ |\mathrm{~N}|^{\mathrm{a}} & 0.042 & 0.006 & 0 & 0.010 & 0.025 \\ \left|\mathrm{C}_{\alpha}\right|^{\mathrm{a}} & 0.028 & 0.013 & 0 & 0.009 & 0.017 \\ \left|\mathrm{C}_{\beta}\right|^{\mathrm{a}} & 0.009 & 0.007 & 0 & 0.006 & 0.010 \\ \left|\mathrm{C}_{\mathrm{m}}\right|^{\mathrm{a}} & 0.126 & 0.015 & 0 & 0.002 & 0.004\end{array}$

a) $\left|C_{\alpha}\right|,\left|C_{\beta}\right|,\left|C_{m}\right|$, and $|N|$ are the mean absolute displacement of the $\alpha$-, $\beta$-, meso-carbons, and pyrrole nitrogens from the mean plane of the porphyrin ring.

(1) PP and HPP

PP and HPP both are planar macrocycle without distortion geometries according to their dihedral angles being quite close to two perfect values, $180^{\circ}$ and $0^{\circ}$, which are features of a plane, as shown in Table 1. However, bond angels of PP and HPP, $\mathrm{C}_{\alpha}-\mathrm{N}-\mathrm{C}_{\alpha}$ and $\mathrm{C}_{\alpha}-\mathrm{C}_{\mathrm{m}}-\mathrm{C}_{\alpha}$, show relatively large deviations with respect to the $\mathrm{H}_{2} \mathrm{PP}$ structural parameters. Correspondingly, the mean absolute displacements of meso-carbons and pyrrole nitrogens, $\left|\mathrm{C}_{\mathrm{m}}\right|$ and $|\mathrm{N}|$, are still obvious for PP. As for the case of HPP, the reason of less value of $|\mathrm{N}|$ may lie in one hydrogen atom bounding to the interior pyrrole nitrogen, which is partially similar to the free base porphine ring.

\section{(2) $\mathrm{H}_{3} \mathrm{PP}$ and $\mathrm{H}_{4} \mathrm{PP}$}

Monoprotonation and diprotonation of porphyrin derivatives, named $\mathrm{H}_{3} \mathrm{PP}$ and $\mathrm{H}_{4} \mathrm{PP}$, are relatively common in contrast with other porphyrin species. By comparison to PP and HPP, $\mathrm{H}_{3} \mathrm{PP}$ and $\mathrm{H}_{4} \mathrm{PP}$ display slight values of $\left|\mathrm{C}_{\alpha}\right|,\left|\mathrm{C}_{\beta}\right|,\left|\mathrm{C}_{\mathrm{m}}\right|$ and $|\mathrm{N}|$ following the order, the mean absolute displacement 
of $\mathrm{H}_{3} \mathrm{PP}$ is smaller that of $\mathrm{H}_{4} \mathrm{PP}$. In addition, both protonated species follow the same order in terms of the mean absolute displacement of the $\alpha-, \beta-$, meso-carbons, and pyrrole nitrogens from the mean plane of the porphyrin ring, $|\mathrm{N}|>\left|\mathrm{C}_{\alpha}\right|>\left|\mathrm{C}_{\beta}\right|>\left|\mathrm{C}_{\mathrm{m}}\right|$. In the meantime, the $\mathrm{C}_{\alpha}-\mathrm{N}-\mathrm{C}_{\alpha}$ of bond angel slightly decreases from $110.8^{\circ}$ to $108.0^{\circ}$ by $110.5^{\circ}$ with expanding the $\mathrm{C}_{\alpha}-\mathrm{C}_{\mathrm{m}}-\mathrm{C}_{\alpha}$ of bond angel step by step from $121.1^{\circ}$ to $128.0^{\circ}$ then $128.2^{\circ}$ for $\mathrm{H}_{2} \mathrm{PP}, \mathrm{H}_{3} \mathrm{PP}$ and $\mathrm{H}_{4} \mathrm{PP}$. Moreover, the $\mathrm{H}_{\mathrm{N}}-\mathrm{N}-\mathrm{C}_{\alpha}-\mathrm{C}_{\beta}$ of dihedral angel appears distinctly an decrease by about $46^{\circ}$ and the $\mathrm{H}_{\mathrm{N}}-\mathrm{N}-\mathrm{C}_{\alpha}-\mathrm{C}_{\mathrm{m}}$ of dihedral angel exhibits synchronously the acutest augment from $0.0^{\circ}$ to $34.2^{\circ}$ and finally $51.2^{\circ}$. These results undoubtedly suggest that the additionally protonation of the free base macrocycle leads to the distortion of porphyrin core, which are in agreement with the previous crystal data and quantum calculation $[25,38]$.

\section{(3) $\mathrm{H}_{5} \mathrm{PP}$ and $\mathrm{H}_{6} \mathrm{PP}$}

Even though porphyrin monocations occasionally could be detectable due to the high non-planarity of its core porphyrin [5] or hyperporphyrin effects [10,39], the protonation of the interior pyrrole nitrogen atoms of the porphyrin macrocycle and analogues $[27,40]$ are generally inseparable. Therefore, in an attempt to confirm the final states of protonation of porphyrin cores, it is worthwhile to investigate for completeness sake whether $\mathrm{H}_{5} \mathrm{PP}$ and $\mathrm{H}_{6} \mathrm{PP}$ are ruled out.

Table 2. Selected structural parameters of optimized geometries of $\mathrm{H}_{5} \mathrm{PP}$ and $\mathrm{H}_{6} \mathrm{PP}$.

\begin{tabular}{lccccccc}
\hline & $\mathrm{H}_{2} \mathrm{PP}^{\mathrm{b}}$ & $\mathrm{H}_{5} \mathrm{PP}^{\mathrm{b}}$ & $\mathrm{H}_{6} \mathrm{PP}^{\mathrm{b}}$ & $\mathrm{H}_{5} \mathrm{PP}^{\mathrm{c}}$ & $\mathrm{H}_{6} \mathrm{PP}^{\mathrm{c}}$ & $\mathrm{H}_{5} \mathrm{PP}^{\mathrm{d}}$ & $\mathrm{H}_{6} \mathrm{PP}^{\mathrm{d}}$ \\
\hline \multicolumn{2}{l}{ Bond distances $(\AA)$} & & & & & & \\
$\mathrm{C}_{\beta}-\mathrm{C}_{\beta}$ & 1.356 & 1.384 & 1.391 & 1.384 & 1.390 & 1.383 & 1.390 \\
$\mathrm{C}_{\alpha}-\mathrm{C}_{\beta}$ & 1.460 & 1.423 & 1.420 & 1.423 & 1.419 & 1.423 & 1.419 \\
$\mathrm{C}_{\alpha}-\mathrm{N}$ & 1.372 & 1.413 & 1.430 & 1.413 & 1.430 & 1.412 & 1.426 \\
$\mathrm{C}_{\alpha}-\mathrm{C}_{\mathrm{m}}$ & 1.394 & 1.399 & 1.408 & 1.399 & 1.408 & 1.397 & 1.429 \\
$\mathrm{C}_{\beta}-\mathrm{H}_{\beta}$ & 1.081 & 1.084 & 1.086 & 1.084 & 1.086 & 1.084 & 1.086 \\
$\mathrm{C}_{\mathrm{m}}-\mathrm{H}_{\mathrm{m}}$ & 1.086 & 1.087 & 1.090 & 1.087 & 1.090 & 1.087 & 1.090 \\
$\mathrm{~N}-\mathrm{H}_{\mathrm{N}}$ & 1.014 & 1.013 & 1.030 & 1.013 & 1.029 & 1.013 & 1.029 \\
Bond angles (deg.) & & & & & &
\end{tabular}




\begin{tabular}{|c|c|c|c|c|c|c|c|}
\hline $\mathrm{C}_{\alpha}-\mathrm{C}_{\mathrm{m}}-\mathrm{C}_{\alpha}$ & 121.1 & 129.5 & 129.5 & 129.5 & 129.9 & 129.3 & 129.3 \\
\hline $\mathrm{C}_{\alpha}-\mathrm{N}-\mathrm{C}_{\alpha}$ & 110.8 & 109.0 & 106.5 & 109.0 & 106.3 & 108.8 & 106.3 \\
\hline $\mathrm{C}_{\alpha}-\mathrm{C}_{\beta}-\mathrm{C}_{\beta}$ & 108.0 & 108.3 & 108.5 & 108.4 & 108.4 & 108.4 & 108.3 \\
\hline $\mathrm{N}-\mathrm{C}_{\alpha}-\mathrm{C}_{\beta}$ & 106.6 & 107.6 & 105.8 & 107.6 & 105.6 & 107.8 & 105.3 \\
\hline $\mathrm{N}-\mathrm{C}_{\alpha}-\mathrm{C}_{\mathrm{m}}$ & 125.5 & 124.5 & 125.4 & 124.5 & 125.6 & 124.5 & 125.3 \\
\hline $\mathrm{C}_{\beta}-\mathrm{C}_{\beta}-\mathrm{H}_{\beta}$ & 127.7 & 126.7 & 126.2 & 126.7 & 126.2 & 126.8 & 126.5 \\
\hline $\mathrm{C}_{\alpha}-\mathrm{C}_{\mathrm{m}}-\mathrm{H}_{\mathrm{m}}$ & 115.9 & 114.7 & 114.6 & 114.7 & 114.4 & 114.8 & 115.06 \\
\hline $\mathrm{C}_{\alpha}-\mathrm{N}-\mathrm{H}_{\mathrm{N}}$ & 124.6 & 120.6 & 112.5 & 120.6 & 112.4 & 120.5 & 113.8 \\
\hline \multicolumn{8}{|c|}{ Dihedral angles (deg.) } \\
\hline $\mathrm{N}-\mathrm{C}_{\alpha}-\mathrm{C}_{\beta}-\mathrm{H}_{\beta}$ & 180.0 & 176.0 & 176.4 & 176.0 & 176.6 & 176.0 & 176.5 \\
\hline $\mathrm{C}_{\mathrm{m}}-\mathrm{C}_{\alpha}-\mathrm{C}_{\beta}-\mathrm{C}_{\beta}$ & 180.0 & 179.6 & 175.0 & 179.6 & 174.1 & 179.1 & 175.5 \\
\hline $\mathrm{C}_{\alpha}-\mathrm{C}_{\beta}-\mathrm{C}_{\beta}-\mathrm{C}_{\alpha}$ & 0.0 & 0.4 & 0.7 & 0.4 & 0.0 & 0.4 & 0.0 \\
\hline $\mathrm{N}-\mathrm{C}_{\alpha}-\mathrm{C}_{\beta}-\mathrm{C}_{\beta}$ & 0.0 & 1.3 & 0.7 & 1.3 & 4.9 & 1.5 & 7.7 \\
\hline $\mathrm{H}_{\mathrm{N}}-\mathrm{N}-\mathrm{C}_{\alpha}-\mathrm{C}_{\mathrm{m}}$ & 0.0 & 43.5 & 62.9 & 43.5 & 62.6 & 42.7 & 58.1 \\
\hline $\mathrm{H}_{\mathrm{N}}-\mathrm{N}-\mathrm{C}_{\alpha}-\mathrm{C}_{\beta}$ & 180.0 & 137.3 & 122.9 & 137.3 & 123.3 & 137.8 & 127.0 \\
\hline $\mathrm{N}-\mathrm{C}_{\alpha}-\mathrm{C}_{\mathrm{m}}-\mathrm{H}_{\mathrm{m}}$ & 180.0 & 169.3 & 175.2 & 169.3 & 176.3 & 169.3 & 176.2 \\
\hline $\mathrm{N}-\mathrm{C}_{\alpha}-\mathrm{C}_{\mathrm{m}}-\mathrm{C}_{\alpha}$ & 0.0 & 1.3 & 11.0 & 2.22 & 12.6 & 1.91 & 17.3 \\
\hline $\mathrm{C}_{\alpha}-\mathrm{C}_{\mathrm{m}}-\mathrm{C}_{\alpha}-\mathrm{C}_{\beta}$ & 180.0 & 163.5 & 162.2 & 163.6 & 160.4 & 163.8 & 156.6 \\
\hline $\mathrm{H}_{\mathrm{m}}-\mathrm{C}_{\mathrm{m}}-\mathrm{C}_{\alpha}-\mathrm{C}_{\beta}$ & 0.0 & 11.7 & 11.5 & 11.7 & 12.9 & 11.4 & 16.8 \\
\hline$|\mathrm{N}|^{\mathrm{a}}$ & 0 & 0.056 & 0.091 & 0.061 & 0.099 & 0.061 & 0.099 \\
\hline$\left|\mathrm{C}_{\alpha}\right|^{\mathrm{a}}$ & 0 & 0.033 & 0.049 & 0.032 & 0.045 & 0.031 & 0.050 \\
\hline$\left|\mathrm{C}_{\beta}\right|^{\mathrm{a}}$ & 0 & 0.016 & 0.023 & 0.017 & 0.025 & 0.018 & 0.012 \\
\hline$\left|\mathrm{C}_{\mathrm{m}}\right|^{\mathrm{a}}$ & 0 & 0.005 & 0.005 & 0.005 & 0.002 & 0.003 & 0.019 \\
\hline
\end{tabular}

a) $\left|C_{\alpha}\right|,\left|C_{\beta}\right|,\left|C_{m}\right|$, and $|N|$ are the mean absolute displacement of the $\alpha-, \beta-$, meso-carbons, and pyrrole nitrogens from the mean plane of the porphyrin ring. b) by B3LYP/6-31G(d,p) calculations. c) by B3LYP/6-31+G(d,p) calculations. d) by B3LYP/6-31+G(d,p) calculations with dispersion correction.

Table 2 lists selected structural parameters of optimized geometries of $\mathrm{H}_{5} \mathrm{PP}$ and $\mathrm{H}_{6} \mathrm{PP}$ calculated at B3LYP/6-31G(d,p) level, B3LYP/6-31+G(d,p) level and B3LYP/6-31+G(d,p) level corrected 
with dispersion interaction. Compared with 6-31G(d,p) basis set, the 6-31+G(d,p) calculation with or without dispersion correction both gave a slightly larger $|\mathrm{N}|$ by $0.005 \AA$ for $\mathrm{H}_{5} \mathrm{PP}$ and by 0.008 $\AA$ for $\mathrm{H}_{6} \mathrm{PP}$. The $6-31+\mathrm{G}(\mathrm{d}, \mathrm{p})$ calculation with dispersion correction, which is relatively expensive, shown obvious modification for $\mathrm{H}_{6} \mathrm{PP}$ by a large $\left|\mathrm{C}_{\mathrm{m}}\right|$ of $0.019 \AA$ and a small $\left|\mathrm{C}_{\beta}\right|$ of $0.012 \AA$ corresponding to $\left|\mathrm{C}_{\mathrm{m}}\right|$ of $0.005 \AA$ and $\left|\mathrm{C}_{\beta}\right|$ of $0.023 \AA$, which may be due to the crowded hydrogen atoms bounded to the inner-N atoms. Considering both accuracy and expense, the basis set 6-31G(d,p) is applicable for calculation of $\mathrm{H}_{5} \mathrm{PP}$ and $\mathrm{H}_{6} \mathrm{PP}$ since porphyrin derivatives are generally large molecules. The dispersion correction is suggested to employ for discussion mainly on $\mathrm{H}_{6} \mathrm{PP}$ which contains crowded hydrogen atoms at the center of the porphine ring.

Globally, the possible further protonated species, $\mathrm{H}_{5} \mathrm{PP}$ and $\mathrm{H}_{6} \mathrm{PP}$, remain the same trend as $\mathrm{H}_{3} \mathrm{PP}$ and $\mathrm{H}_{4} \mathrm{PP}$. According to the B3LYP/6-31+G(d,p) calculation, when the fifth and sixth protons bound to the protonated interior pyrrole nitrogens, $\left|\mathrm{C}_{\alpha}\right|,\left|\mathrm{C}_{\beta}\right|$ and $|\mathrm{N}|$ change larger, from $0.032 \AA$ to $0.045 \AA, 0.017 \AA$ to $0.025 \AA$, and $0.061 \AA$ to $0.099 \AA$, respectively. The slightly changed $\left|C_{m}\right|$, along with the similar $\mathrm{C}_{\alpha}-\mathrm{C}_{\mathrm{m}}-\mathrm{C}_{\alpha}$ of bond angels $\left(129.3^{\circ}\right.$ to $\left.129.9^{\circ}\right)$, manifests that the macrocycle skeleton is unable to further change. The distortion of porphine ring continuously becomes more acute, which eventually affords $62.6^{\circ}$ of the $\mathrm{H}_{\mathrm{N}}-\mathrm{N}-\mathrm{C}_{\alpha}-\mathrm{C}_{\mathrm{m}}$ of dihedral angel and $56.7^{\circ}$ of abatement in the $\mathrm{H}_{\mathrm{N}}-\mathrm{N}-\mathrm{C}_{\alpha}-\mathrm{C}_{\beta}$ of dihedral angel. Actually, $\mathrm{C}_{\alpha}-\mathrm{N}-\mathrm{C}_{\alpha}$ and $\mathrm{C}_{\alpha}-\mathrm{N}-\mathrm{H}_{\mathrm{N}}$ of bond angels, that are of $106.3^{\circ}$ and $112.4^{\circ}$, are significantly different from the corresponding bond angels of aromatic pyrrole, $109.8^{\circ}$ and $125.1^{\circ}$, which enables us to conclude that the aromaticity of two of four pyrrole rings in the macrocycle structure might be broken. Fortunately, the aromaticity of macrocycle ring doesn't depend on pyrrole ring thoroughly as explicated by some analogues such as nitrogen-confused porphyrin [41,42] and chlorines and bacteriochlorins [43]. It is worthwhile to mention that even though the proton bonded to the interior pyrrole nitrogen are significantly tilted from the pyrrole planes, the porphyrin ring is relatively saddle-distorted from the mean plane, with the pyrrole ring $\left(\mathrm{C}_{\alpha}-\mathrm{C}_{\mathrm{m}}-\mathrm{C}_{\alpha}-\mathrm{C}_{\beta}\right)$ tilted with respect to the porphyrin mean-plane by the maximum of $16.4^{\circ}$ for $\mathrm{H}_{5} \mathrm{PP}$ and $19.6^{\circ}$ for $\mathrm{H}_{6} \mathrm{PP}$. This angle of tilt is obviously smaller than the corresponding X-ray values of $\mathrm{H}_{4} \mathrm{TPP}^{2+}\left(33^{\circ}\right)$ and $\mathrm{H}_{4} \mathrm{TPyP}^{2+}\left(27.8^{\circ}\right)$ [44], which may be attributed to the effects of the crystal packing and the presence of meso-subtituents in $\mathrm{H}_{4} \mathrm{TPP}^{2+}$ and $\mathrm{H}_{4} \mathrm{TPyP}^{2+}$ solids. 


\subsection{Formation Gibbs free energies of deprotonated and protonated species of porphyrins}

Recently, free energy of a series of meso-aryl-substituted N-confused porphyrins and porphyrins calculated at the B3LYP/6-31G** level revealed a multi-step process for deprotonation and protonation of the regular porphyrins and their analogues [27]. Our calculation at B3LYP/6-31+G(d,p) including $\mathrm{H}_{5} \mathrm{PP}$ and $\mathrm{H}_{6} \mathrm{PP}$ not only confirms these results but also affords an interesting clue to the final point of protonation of porphyrin macrocycle.

Deprotonation of the free base porphyrins afford monoanionic- and dianionic- species by loosing one and two protons, along with an endothermic energy of $378.1 \mathrm{kcal} \cdot \mathrm{mol}^{-1}$ at the first step and then $478.6 \mathrm{kcal} \cdot \mathrm{mol}^{-1}$ at the second step. By contrast, through the protonation reaction the porphyrin free base gives rise to formation of monocationic- and dicationic- species by accepting one or two hydrogen ions, accompanying with an exothermic energy of $239.2 \mathrm{kcal} \cdot \mathrm{mol}^{-1}$ firstly and $154.7 \mathrm{kcal} \cdot \mathrm{mol}^{-1}$ secondly. These calculated results are consistent with the trend of relative energy data recently reported by Hiroyuki Furuta et al in gas phase at the B3LYP/6-31G** theory level [27].

It is seemingly possible that the proton can be further attached onto the interior pyrrole nitrogen of dicationic porphyrin ring. Similarly, hydrogen-bonded clusters protonated $\mathrm{C}_{4} \mathrm{H}_{5} \mathrm{~N}-\left(\mathrm{H}_{2} \mathrm{O}\right)_{n} \mathrm{H}^{+}$were obtained and investigated using a time-of-flight mass spectrometer. [45] Interestingly, the free energy difference, $\Delta \mathrm{G}$, between the dicationic species and its protonated species becomes smaller, occasionally endothermic instead of exothermic, when further protonation takes place (Figure 2). For the formation of $\mathrm{H}_{5} \mathrm{PP}, \Delta \mathrm{G}$ is $-46.9 \mathrm{kcal} \cdot \mathrm{mol}^{-1}$ and for $\mathrm{H}_{6} \mathrm{PP}, \Delta \mathrm{G}$ is $+32.2 \mathrm{kcal} \cdot \mathrm{mol}^{-1}$. It is

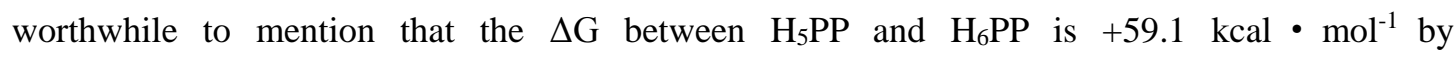
B3LYP/6-31+G(d,p) calculation including dispersion.

Surprisingly, using SCRF based on the model IEFPCM to build a continuum of uniform dielectric constant simulating the solvation of water, the calculation gave an obviously different trend for the formation of $\mathrm{H}_{5} \mathrm{PP}$ and $\mathrm{H}_{6} \mathrm{PP}$. Corresponding to formation of monoanionic, dianionic, monocationic, dicationic, tricationic and tetracationic species by removal or addition of one proton, the $\Delta \mathrm{G}$ are $+336.4,+364.1,-270.7,-257.8,-218.7$ and $-211.1 \mathrm{kcal} \cdot \mathrm{mol}^{-1}$, respectively. Taking on 
these calculation results, we can reasonably conclude that the real termination point of protonation of the free base porphine is $\mathrm{H}_{5} \mathrm{PP}$ or $\mathrm{H}_{6} \mathrm{PP}$ rather than dicationic species $\mathrm{H}_{4} \mathrm{PP}$ depending on its structural features and solvation effects.

Scheme 2. Protonation reaction of porphine species.

Figure 2. The $\Delta \mathrm{G}\left(\mathrm{kcal} \cdot \mathrm{mol}^{-1}\right)$ for formation of the protonated and deprotonated porphine species. “-” calculated by B3LYP/6-31+G(d,p), “-” calculated by CPCM/6-31+G(d,p)//B3LYP/6-31+G(d,p) with water as an implicit solvent.

\subsection{Distances of inner hydrogen atoms and aromaticity of porphyrins}

In general, it is widely accepted $[44,46]$ that the steric hindrance of the central hydrogen atoms is the main cause for the ring saddle-distortion of porphyrin diacids, even though the possible role of electrostatic repulsion of the positive charges on $\mathrm{HN}$ atoms can not be completely excluded. Distances of selected two inner hydrogen atoms calculated at the B3LYP/6-31G(d,p) level for protonation species of the free base of porphine are listed in Table 3.

Table 3. Distances ( $\AA$ ) between selected two inner hydrogen atoms at the B3LYP/6-31G(d,p)

level.

\begin{tabular}{llllll}
\hline Species & $\mathrm{H}_{2} \mathrm{PP}$ & $\mathrm{H}_{3} \mathrm{PP}$ & $\mathrm{H}_{4} \mathrm{PP}$ & $\mathrm{H}_{5} \mathrm{PP}$ & $\mathrm{H}_{6} \mathrm{PP}$ \\
\hline $\mathrm{H}_{1}-\mathrm{H}_{2}$ & 2.206 & 2.300 & 2.287 & 2.649 & 3.138 \\
$\mathrm{H}_{1}-\mathrm{H}_{3}$ & & 2.072 & 2.166 & 2.530 & 2.667 \\
$\mathrm{H}_{2}-\mathrm{H}_{3}$ & & 2.072 & 2.166 & 2.505 & 3.368 \\
$\mathrm{H}_{1}-\mathrm{H}_{4}$ & & & 2.166 & 2.530 & 2.367 \\
$\mathrm{H}_{2}-\mathrm{H}_{4}$ & & & 2.166 & 2.505 & 2.521 \\
$\mathrm{H}_{3}-\mathrm{H}_{4}$ & & & & 3.113 & 4.221 \\
$\mathrm{H}_{1}-\mathrm{H}_{5}$ & & & & 1.671 & 1.660 \\
$\mathrm{H}_{3}-\mathrm{H}_{5}$ & & & & 2.328 & 2.522 \\
$\mathrm{H}_{4}-\mathrm{H}_{5}$ & & & & 2.328 & 3.369
\end{tabular}




$$
\begin{aligned}
& \mathrm{H}_{3}-\mathrm{H}_{6} \\
& \mathrm{H}_{2}-\mathrm{H}_{6}
\end{aligned}
$$

In the cases of $\mathrm{H}_{3} \mathrm{PP}$ and $\mathrm{H}_{4} \mathrm{PP}$, the firstly and secondly additional hydrogen atoms indeed compress two hydrogen atoms distance from $2.206 \AA$ to $2.072 \AA$ for $\mathrm{H}_{3} \mathrm{PP}$, to $2.166 \AA$ for $\mathrm{H}_{4} \mathrm{PP}$, which can be attributed to the transannular crowding between the four hydrogen atoms of the pyrrole nitrogen atoms. In contrast, in the cases of $\mathrm{H}_{5} \mathrm{PP}$ and $\mathrm{H}_{6} \mathrm{PP}$ every distance between two hydrogen atoms bonded to different nitrogen atoms is larger than $2.206 \AA$. Two hydrogen atoms attached to a same nitrogen atom are $1.671 \AA$ for $\mathrm{H}_{5} \mathrm{PP}\left(\mathrm{H}_{1}-\mathrm{H}_{5}\right)$, and $1.660 \AA$ for $\mathrm{H}_{6} \mathrm{PP}\left(\mathrm{H}_{1}-\mathrm{H}_{5}\right.$ and $\left.\mathrm{H}_{2}-\mathrm{H}_{6}\right)$ apart, which is slightly distant than $1.651 \AA$ of the distance of two hydrogen atoms in amine molecule. Obviously, the crucial factor to evidence the probability of $\mathrm{H}_{5} \mathrm{PP}$ and $\mathrm{H}_{6} \mathrm{PP}$ is protonation of the interior pyrrole nitrogen atoms since the steric congestion of the central hydrogen atoms doesn't occur.

Table 4. Summary of Natural Population Analysis for $\mathrm{H}_{5} \mathrm{PP}$ and $\mathrm{H}_{6} \mathrm{PP}$ calculated at the B3LYP/6-31G(d,p) level.

\begin{tabular}{lll}
\hline Atom & $\mathrm{H}_{5} \mathrm{PP}$ & $\mathrm{H}_{6} \mathrm{PP}$ \\
\hline $\mathrm{N}_{\mathrm{H} 1}$ & 7.59 & 7.59 \\
$\mathrm{~N}_{\mathrm{H} 2}$ & 7.58 & 7.59 \\
$\mathrm{~N}_{\mathrm{H} 3}$ & 7.62 & 7.67 \\
$\mathrm{~N}_{\mathrm{H} 4}$ & 7.62 & 7.67 \\
meso- $\mathrm{C}_{13}$ & 6.12 & 6.14 \\
meso- $\mathrm{C}_{23}$ & 6.07 & 6.08 \\
meso- $_{24}$ & 6.07 & 6.14 \\
meso- $\mathrm{C}_{14}$ & 6.12 & 6.08 \\
\hline
\end{tabular}

Notes: $1 . \mathrm{N}_{\mathrm{H} 1}, \mathrm{~N}_{\mathrm{H} 2}, \mathrm{~N}_{\mathrm{H} 3}$, and $\mathrm{N}_{\mathrm{H} 4}$ mean the nitrogen atom bonded to $\mathrm{H}_{1}, \mathrm{H}_{2}, \mathrm{H}_{3}$, and $\mathrm{H}_{4} .2$. meso- $\mathrm{C}_{13}$, meso- $\mathrm{C}_{23}$, meso- $\mathrm{C}_{24}$, and meso- $\mathrm{C}_{14}$ mean the meso-carbon linked to two pyrrole rings including $\mathrm{H}_{1}$ and $\mathrm{H}_{3}, \mathrm{H}_{2}$ and $\mathrm{H}_{3}, \mathrm{H}_{2}$ and $\mathrm{H}_{4}$, and $\mathrm{H}_{1}$ and $\mathrm{H}_{4}$ atoms. 
Figure 3. Natural Population Analysis for $\mathrm{H}_{5} \mathrm{PP}$ and $\mathrm{H}_{6} \mathrm{PP}$ calculated at the B3LYP/6-31G(d,p)

level.

Population analysis is the study of charge distribution within molecules in an attempt to model partial charge magnitude and location within a molecule, which can be thought of as a rigorous version of assigning partial charges on the atoms like chemists often do in Lewis dot structures [47]. As can be seen from Table 4 , the total 3 positive charges of $\mathrm{H}_{5} \mathrm{PP}$ are mainly assigned to $\alpha$ and $\beta$-carbon atoms and to lower extent to the interior pyrrole nitrogen atoms, while the four meso-carbon atoms are added up less negative charges. Because each of $\mathrm{N}_{\mathrm{H} 1}$ and $\mathrm{N}_{\mathrm{H} 2}$ attaches to two hydrogen atoms, they are added up partial positive charges. The total four positive charges of $\mathrm{H}_{6} \mathrm{PP}$ are mainly assigned to $\alpha$ - and $\beta$-carbon atoms, the four meso-carbon atoms, $\mathrm{N}_{\mathrm{H} 3}$ and $\mathrm{N}_{\mathrm{H} 4}$ atoms hold partial negative charges. Correspondingly, carbon-carbon bond lengths show a similar equalization trend (Table 1 and Table 2). Compared to carbon-carbon bond lengths of $\mathrm{H}_{2} \mathrm{PP}$, in the cases of $\mathrm{H}_{5} \mathrm{PP}$ and $\mathrm{H}_{6} \mathrm{PP}, \mathrm{C}_{\beta}-\mathrm{C}_{\beta}$ and $\mathrm{C}_{\alpha}-\mathrm{C}_{\mathrm{m}}$ get longer by $0.028-0.035 \AA$ and $0.005-0.014 \AA$ while $\mathrm{C}_{\alpha}-\mathrm{C}_{\beta}$ bond lengths decrease by $0.020-0.023 \AA$. Bond length equalization is a characteristic feature of aromatic porphyrinoids and can be used to identify preferred conjugation pathways in these molecules. Reliable bond lengths are available from high-level theoretical calculations, especially those employing the density functional theory [48]. Therefore, the equalization of bond lengths significantly suggests that the macrocycle improves its aromaticity. Meanwhile, $\mathrm{C}_{\alpha}-\mathrm{N}$ bonds lengthen 0.041-0.058 $\AA$ obviously, indicating the increase of single bond component in $\mathrm{C}_{\alpha}$ - $\mathrm{N}$ bonds which implies that the relevant pyrrole rings loose aromaticity.

\subsection{Effects of meso-substituents}

Crystal data of porphyrins have delineated that the peripheral substituents of the porphyrin affect significantly the overall molecular flexibility [38]. In an attempt to rationalize effects of common meso-substituents on the protonated species of porphyrin diacids $\mathrm{H}_{5} \mathrm{PP}$ and $\mathrm{H}_{6} \mathrm{PP}$, the relative energies of diacids and their protonated species of water-soluble porphyrins, tetra(p-carboxylphenyl)porphyrin (TCPP) and tetra(meso-pyridyl)porphyrin (TPyP) were calculated (Table 5).

Table 5. The relative energies $\left(\mathrm{kcal} \cdot \mathrm{mol}^{-1}\right)$ for protonated species of TCPP and TPyP calculated at 
the B3LYP/6-31G(d,p) level .

\begin{tabular}{llll}
\hline & $\mathrm{H}_{2} \mathrm{PP} \rightarrow \mathrm{H}_{4} \mathrm{PP}$ & $\mathrm{H}_{4} \mathrm{PP} \rightarrow \mathrm{H}_{5} \mathrm{PP}$ & $\mathrm{H}_{5} \mathrm{PP} \rightarrow \mathrm{H}_{6} \mathrm{PP}$ \\
\hline TCPP & -449.3 & -63.1 & -28.3 \\
TPyP & -418.1 & -64.8 & +7.3 \\
\hline
\end{tabular}

Meso-substituents of these two porphyrins explicitly influence the relative energies of their diacids, triacids and tetraacids, leading to enlarging the energy gaps of $\mathrm{H}_{2} \mathrm{PP} \rightarrow \mathrm{H}_{4} \mathrm{PP}, \mathrm{H}_{4} \mathrm{PP} \rightarrow \mathrm{H}_{5} \mathrm{PP}$ and $\mathrm{H}_{5} \mathrm{PP} \rightarrow \mathrm{H}_{6} \mathrm{PP}$. In the case of TPyP, similarly to the porphine ring, its $\mathrm{H}_{5} \mathrm{PP}$ species attaches one proton by absorbing $7.3 \mathrm{kcal} \cdot \mathrm{mol}^{-1}$ of energy. In contrast with this case, particularly, the energy gap between $\mathrm{H}_{5} \mathrm{PP}$ and $\mathrm{H}_{6} \mathrm{PP}$ species of TCPP is conversely exothermic rather than endothermic. Thus, the energetically stable species is $\mathrm{H}_{5} \mathrm{PP}$ for TPyP but $\mathrm{H}_{6} \mathrm{PP}$ for TCPP. Considering the previous finding that the relative stability and magnitude of distortion of porphyrin diacids increases as the steric bulk of the substituents increases [49], these changes of energy gaps can be reasonably attributed to the severe distortion of porphyrin core rings resulted from the steric congestion of different peripheral substituents of porphyrins.

Undoubtedly, since proton has large hydration energy, the protonation of porphyrins in aqueous solutions may be harder so that many porphyrins would hardly form triacidic or tetraacidic species. Fortunately, natural compounds and synthesized porphyrins can provide versatile and rich systems to render some triacid and tetraacid species possible. For an example, in general, adenosine triphosphate (ATP) can support energetically biological processes which are unfavorable. Another example is, multiple methoxyl groups bounded to the porphine ring could enlarge the energy gap between the free base and its triacid, which leads to the possibility to afford triacid species in gas phase.[50] Reasonably, the details of effect of substituents along with other aspects of tri- and tetraacids of porphyrins including solvents, structures, excited state, aromaticity, chemical shifts, spectral absorption, and sequent changes of relevant properties and application in various fields need to be further investigated as soon as possible.

\section{Conclusions}

In summary, all possible deprotonated and protonated species of porphyrins are investigated using 
DFT. Calculations results suggest further protonation of porphyrin diacids afford triacids and tetraacids.

Energetic calculation and optimized structure analyses evidence two protonated species of porphyrin diacids, triacids and tetraacids, are reasonably possible. In particular, based on the analysis of optimized geometries, electronic structures and natural population analysis of protonated species, we confirm theoretically the aromaticity and stability of porphyrin triacid and tetraacid. Crowding inner hydrogen atoms attached to the pyrrole nitrogen atoms leads to distortion of porphyrin core. The peripheral meso-substituents and inner hydrogen atoms affect significantly the overall molecular flexibility. Additional hydrogen atoms attach to the inner nitrogen atoms of protonated porphyrins and give rise to rearrangement of aromatic system involving $\alpha-, \beta-$, and meso-carbons. Triacid or tetraacid is probably the stablest species for different porphyrins depending mainly on the peripheral substituents, which needs to be further investigated. Further protonation of porphyrin diacids might gives a new perspective to explain photochemical, electrochemical, spectroscopic and thermodynamic phenomena in the protonation processes that related to diverse properties of porphyrin and porphyrinoids.

\section{Acknowledgment}

The author is grateful to the National Science Foundation of Hebei Province of China (No. B2008000709 and No. 2013402015). The author also is grateful to the Chinese Scholarship Council (No. 201308130188). In addition, the author thanks Professor Micheal Bühl and Jan Philipp Götze (School of science, University of St Andrews, North Haugh, St Andrews, Fife, KY16 9ST, Scotland, United Kingdom) for many helpful favors and discussion on this issue, and a lot of thanks to their colleague Dr. Herbert Fruchtl for his help in using Gaussian 09 software when I studied in University of St Andrews.

\section{References}

[1] W. S. Li, T. Aida, Dendrimer porphyrins and phthalocyanines, Chem. Rev. 109 (2009) 6047-6076.

[2] W. Maesl, W. Dehaen, Synthetic aspects of porphyrin dendrimers, Eur. J. Org. Chem. 28 (2009) 4719-4752.

[3] Y. Zhang, M. X. Li, M. Y. Lü, R.H. Yang, F. Liu, and K. A. Li, Anion chelation-induced 
porphyrin protonation and its application for chloride anion sensing, J. Phys. Chem. A. 109 (2005) $7442-7448$

[4] H.W. Guo, J.G. Jiang, Y.Y Shi, Y.L. Wang, Y. Wang, and S.J Dong, Sequential Deprotonation of meso-(p-Hydroxyphenyl)porphyrins in DMF: From Hyperporphyrins to Sodium Porphyrin Complexes, J. Phys. Chem. B 110 (2006) 587-594.

[5] S. Thyagarajan, T. Leiding, S. Peterson Årsköld, A. V. Cheprakov, and S. A. Vinogradov, Highly Non-Planar Dendritic Porphyrin for pH Sensing: Observation of Porphyrin Monocation, Inorg. Chem. 49 (2010) 9909-9920.

[6] E. Austin, M. Gouterman, Porphyrins. XXXVII. Absorption and emission of weak complexes with acids, bases, and salts, Bioinorg. Chem. 9 (1978) 281-298.

[7] A. H. Corwin, A. B. Chivvis, R. W. Poor, D. G. Whitten, E. W. Baker, Porphyrin studies. XXXVII. The interpretation of porphyrin and metalloporphyrin spectra, J. Am. Chem. Soc., 90(1968) 6577-6583.

[8] T. Honda, T. Kojima, S. Fukuzumi, Crystal structures and properties of a monoprotonated porphyrin. Chem. Commun, 33(2009) 4994-4996.

[9] N. Hirayama, A. Takenaka, Y. Sasada, E. -I. Watanabe, H. Ogoshi, Z.-I. Yoshida, X-ray crystal structure of octaethylporphinium (monocation) tri-iodide, J. Chem. Soc., Chem. Commun. (1974) $330-331$

[10] A. B. Rudine, B. D. Delfatti, C. C. Wamser, Spectroscopy of protonated tetraphenylporphyrins with amino/carbomethoxy substituents: Hyperporphyrin effects and evidence for a monoprotonated porphyrin, J. Organ. Chem. 78(2013) 6040-6049.

[11] C. Y. Wang, C. C. Wamser, Hyperporphyrin effects in the spectroscopy of protonated porphyrins with 4-aminophenyl and 4-pyridyl meso substituents, J. Phys. Chem. A. 118(2014) 3605-3615.

[12] K.M. Smith (Ed.), Porphyrins and Metalloporphyrins, Elsevier/North-Holland, New York, 1976.

[13] D. Dolphin (Ed.), The Porphyrins, vols. 1-7, Academic Press, New York, 1978.

[14] G.A. Schick, M.R. O’Grady, R.K. Tiwari, Resonance raman scattering from excition-coupled states in porphyrin monolayer assemblies, J. Phys. Chem. 97 (1993) 1339-1345.

[15] D.L. Akins, S. Özcçelik, H.-R. Zhu, C. Guo, Aggregation-enhanced raman scattering of a 
cyanine dye in homogeneous solution, J. Phys. Chem. A, 101 (1997) 3251-3259.

[16] D.L. Akins, S. Ozcelik, H.R. Zhu, C. Guo, Fluorescence decay kinetics and structure of aggregated tetrakis(p-sulfonatophenyl)porphyrin, J. Phys. Chem. 100 (1996) 14390-14396.

[17] D.-M. Chen, T.-J. He, D.-F. Cong, Y.-H. Zhang, F.-C. Liu, Resonance reman spectra and excited-state structure of aggregated tetrakis(4-sulfonatophenyl)porphyrin diacid, J. Phys. Chem. A 105 (2001) 3981-3988.

[18] D.-M. Chen, X.-Y. Li, N.-T. Yu, Y.-H. Zhang, T.-J. He, F.-C. Liu, Resonance raman study of tetrakis(p-sulfonatophenyl)porphyrin diacid $\left(\mathrm{H}_{4}{ }^{2+} \mathrm{TSPP}\right)$ molecular aggregates, Chem. J. Chin. Univ. 20 (1999) 1097-1101.

[19] R.F. Pasternack, K.F. Schaefer, P. Hambright, Resonance light-scattering studies of porphyrin diacid aggregates, Inorg. Chem. 33 (1994) 2062-2065.

[20] A. Ghosh, First-principle quantum chemical studies of porphyrins, Acc. Chem. Res. 31(1998) 189-198.

[21] D. Sundholm, Interpretation of the electronic absorption spectrum of free-base porphyrin using time-dependent density-functional theory, Phys. Chem. Chem. Phys. 55(2000) 2275-2281. [22] A.B.J. Parusel, T. Wondimagegn, A. Ghosh, Do nonplanar porphyrins have red-shifted electronic spectra? A DFT/SCI study and reinvestigation of a recent proposal, J. Am. Chem. Soc. 122 (2000) 6371-6374.

[23] K.A. Nguyen, R. Pachter, Ground state electronic structures and spectra of zinc complexes of porphyrin, tetraazaporphyrin, tetrabenzoporphyrin, and phthalocyanine: A density functional theory study, J. Chem. Phys. 114 (2001) 10757-10767.

[24] A.B.J. Parusel, A. Ghosh, Density functional theory based configuration interaction calculations on the electronic spectra of free-base porphyrin, chlorine, bacteriochlorin, and cisand trans-isobacteriochlorin, J. Phys. Chem. A 104 (2000) 2504-2507.

[25] D.-M. Chen, X. Liu, T.-J. He, F.-C. Liu, Density functional theory investigation of porphyrin diacid: electronic absorption spectrum and conformational inversion, Chem. Phys. 289 (2003) $397-407$

[26] C. J. Ziegler, N. R. Erickson, M. R. Dahlby, V. N. Nemykin, Magnetic circular dichroism spectroscopy of N-confused porphyrin and its ionized forms, J. Phys. Chem. A 117 (2013) 11499-11508. 
[27] R. Sakashita, M. Ishida, and H. Furuta, Spectroscopic and theoretical studies of acid-base behaviors of N-confused porphyrins: Effects of meso-aryl substituents, J. Phys. Chem. A 119 (2015) 1013-1022.

[28] H. J. Callot, R. Cromer, A. Louati, B. Metz, B. Chevrier, Synthesis of N,N'-1,2-vinylidene and 1,2-phenylene bridged porphyrin. X-ray crystal and molecular structure of an N,N'-(diphenyl-1,2-vinylidene)-meso-tetraphenylporphyrin, J. Am. Chem. Soc. 109(1987) 2946-2955

[29] L. T. Nguyen, M. O. Senge, K. M. Smith, One-pot synthesis of regiochemically pure porphyrins from two different pyrroles, Tetrahedron Lett. 35(1994) 7581-7584.

[30] J. Clayden, N. Greeves, S. Warren, P. Wothers, Organic chemistry, Oxford University press Inc. New York, 2001, 1157.

[31] M. J. Frisch, G. W. Trucks, H. B. Schlegel, G. E. Scuseria, M. A. Robb, J. R. Cheeseman, G. Scalmani, V. Barone, B. Mennucci, G. A. Peterson, H. Nakatsuji, M. Caricato, X. Li, H. P. Hratchian, A. F. Izmaylov, J. Bloino, G. Zheng, J. L. Sonnenberg, M. Hada, M. Ehara, K. Toyota, R. Fukuda, J. Hasegawa, M. Ishida, T. Nakajima, Y. Honda, O. Kitao, H. Nakai, T. Vreven, J. A. Montgomery, J. E., Jr. Peralta, F. Ogliaro, M. Bearpark, J. J. Heyd, E. Brothers, K. N. Kudin, V. N. Staroverov, R. Kobayashi, J. Normand, K. Raghavachari, A. Rendell, J. C. Burant, S. S. Iyengar, J. Tomasi, M. Cossi, N. Rega, J. M. Millam, M. Klene, J. E. Knox, J. B. Cross, V. Bakken, C. Adamo, J. Jaramillo, R. Gomperts, R. E. Stratmann, O. Yazyev, A. J. Austin, R. Cammi, C. Pomelli, J. W. Ochterski, R. L. Martin, K. Morokuma, V. G. Zakrzewski, G. A. Voth, P. Salvador, J. J. Dennenberg, S. Dapprich, A. D. Daniels, O. Farkas, J. B. Foresman, J. V. Ortiz, J. Cioslowski, D. J. Fox, Gaussian 09, Revision A.1; Gaussian, Inc.; Wallingford CT. 2009.

[32] A. D. Becke, Density-functional thermochemistry. III. The role of exact exchange, J. Chem. Phys. 98(1993) 5648-5652.

[33] C. Lee, W. Yang, R.G. Parr, Development of the Colle-Salvetti correlation-energy formula into a functional of the electron density, Phys. Rev. B 37(1988)785-789.

[34] P. C. Hariharan and J. A. Pople, The influence of polarization on molecular orbital hydrogenation energies, Theor. Chem. Acc, 28(1973)213-222.

[35] C. Lee, W. Yang, R.G. Parr, Development of the Colle-Salvetti correlation-energy formula into a functional of the electron density, Phys. Rev. B 37(1988) 785-789. 
[36] a) E. R. Johnson, I. D. Mackie, G. A. DiLabio, Dispersion interactions in density-functional theory, J. Phys. Org. Chem. 22(2009) 1127-1135. b) S. Grimme, J. Antony, S. Ehrlich and H. Krieg, A consistent and accurate ab initio parameterization of density functional dispersion correction (DFT-D) for the 94 elements H-Pu, J. Chem. Phys. 132(2010) 154104.

[37] A. Reed, R. Weinstock, F. Weinhold, Natural population analysis, J. Chem. Phys. 83(1985) 735-746.

[38] B.S. Cheng, O.Q. Munro, H.M. Marques, W.R. Scheidt, An analysis of porphyrin molecular flexibility-Use of porphyrin diacids, J. Am. Chem. Soc. 119(1997) 10732-10742.

[39] C. Y. Wang and C. C. Wamser, Hyperporphyrin effects in the spectroscopy of protonated porphyrins with 4-aminophenyl and 4-pyridyl meso substituents, J. Phys. Chem. A, 118(2014) 3605-3615.

[40] R. Kraman and T. C. Bruice, Unusual behavior of 5, 10, 15, 20-tetraphenylporphine diacid toward oxygen bronsted bases, Inorgan. Chem. 31(1992) 2455-2459.

[41] H. Furuta, H. Maeda, and A. Osuka, Theoretical study of stability, structures, and aromaticity of multiply N-confused porphyrins, J. Org. Chem. 66(2001) 8563-8572.

[42] J-I. Aihara, Y. Nakagami, R. Sekine, and M. Makino, Validity and limitations of the bridged annulene model for porphyrins, J. Phys. Chem. A, 116(2012) 11718-11730.

[43] H. Fliegl and D. Sundholm, Aromatic pathways of porphins, chlorines, and bacteriochlorins, J. Org. Chem. 77(2012) 3408-3414.

[44] A. Stone, E.B. Fleischer, The molecular and crystal structure of porphyrin diacids, J. Am. Chem. Soc. 90(1968) 2735-2748.

[45] Y. Li, X-H. Liu, X-Y. Wang, and N-Q. Lou, Multiphoton ionization and ab Initio calculation studies of the hydrogen-bonded clusters $\mathrm{C}_{4} \mathrm{H}_{5} \mathrm{~N}-\left(\mathrm{H}_{2} \mathrm{O}\right)_{n}$, J. Phys. Chem. A 103(1999) 2572-2579.

[46] S.Y. Ma, Theoretical studies on the structural change in the $\mathrm{N}$-protonated meso-tetrakis(p-sulfonatophenyl)porphyrin, Chem. Phys. Lett. 332(5-6) (2000) 603-610.

[47] A. Reed, R. Weinstock, F. Weinhold, Natural population analysis, J. Chem. Phys. 83(1985) 735-746.

[48] M. Stępień and L. Latos-Grażyński, Aromaticity and tautomerism in porphyrins and porphyrinoids, in: R.R. Gupta, Topics in heterocyclic chemistry, Springer-Verlag Berlin Heidelberg, Vol 19, 2009, pp. 83-153. 
[49] E. M. Finnigan, S. Giordani, M. O. Senge and T. McCabe, Structural, spectroscopic, and anion-binding properties of 5,10-porphodimethene, an unusual class of calixphyrins, J. Phys. Chem. A, 114(2010) 2464-2470.

[50] In case of the protonation of four methoxyl groups bounded to $\beta$ positions of the porphine ring $(\mathrm{PP})$, the formation reaction of $\mathrm{PP}$ triacid, $\mathrm{PP}+3 \mathrm{H}_{3} \mathrm{O}^{+}=\left(\mathrm{PP}-\mathrm{H}_{3}\right)^{3+}+3 \mathrm{H}_{2} \mathrm{O}$, is strongly favorable, since the $\Delta \mathrm{G}$ is -0.03024 a.u. according to the brief calculation using B3LYP/3-21G. 


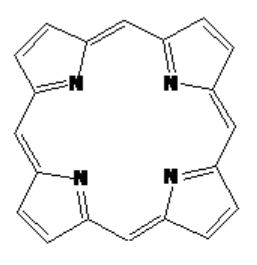

PP

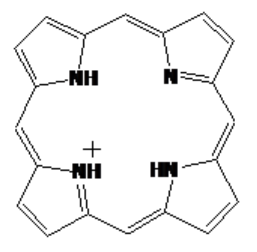

H3 $_{3} \mathbf{P}$

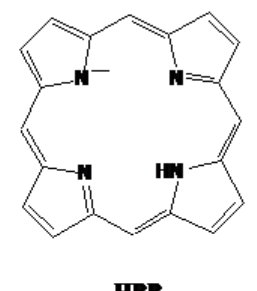

HPP

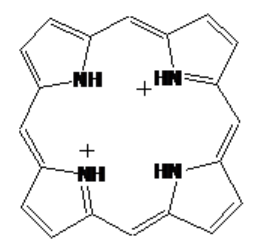

H4P

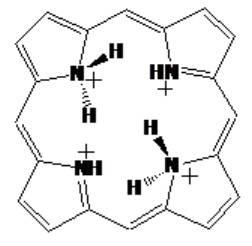

$\mathbf{H}_{6} \mathbf{P P}$

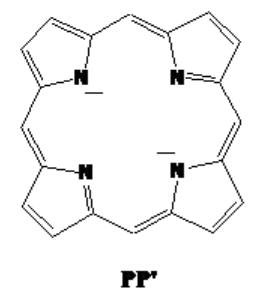

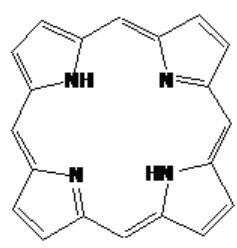

$\mathbf{H}_{2} \mathbf{P P}$

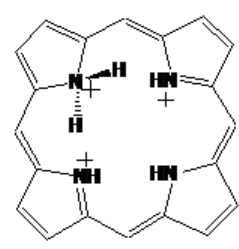

$\mathbf{H}_{5} \mathbf{P P}$ 


$$
\mathrm{H}_{\mathrm{x}} \mathrm{PP}+\mathrm{H}^{+} \longrightarrow \mathrm{H}_{\mathrm{x}+1} \mathrm{PP} \quad \mathrm{x}=0-5
$$




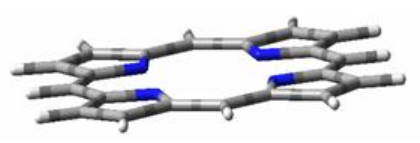

PP

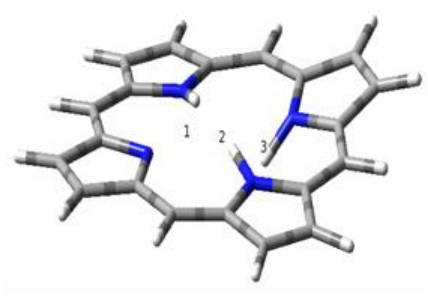

$\mathrm{H}_{3} \mathrm{PP}$

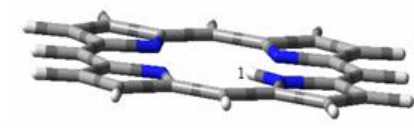

HPP

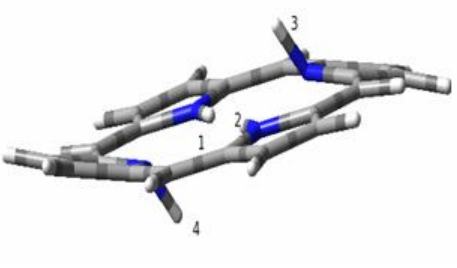

$\mathrm{H}_{4} \mathrm{PP}$

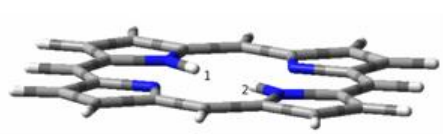

$\mathrm{H}_{2} \mathrm{PP}$

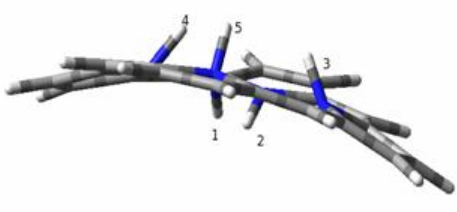

$\mathrm{H}_{5} \mathrm{PP}$

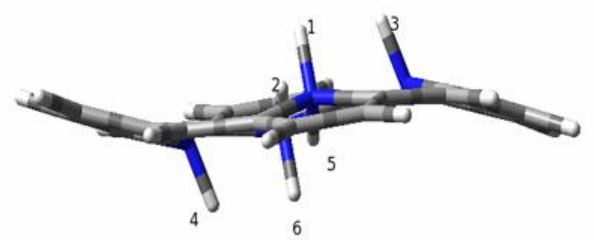

$\mathrm{H}_{6} \mathrm{PP}$ 


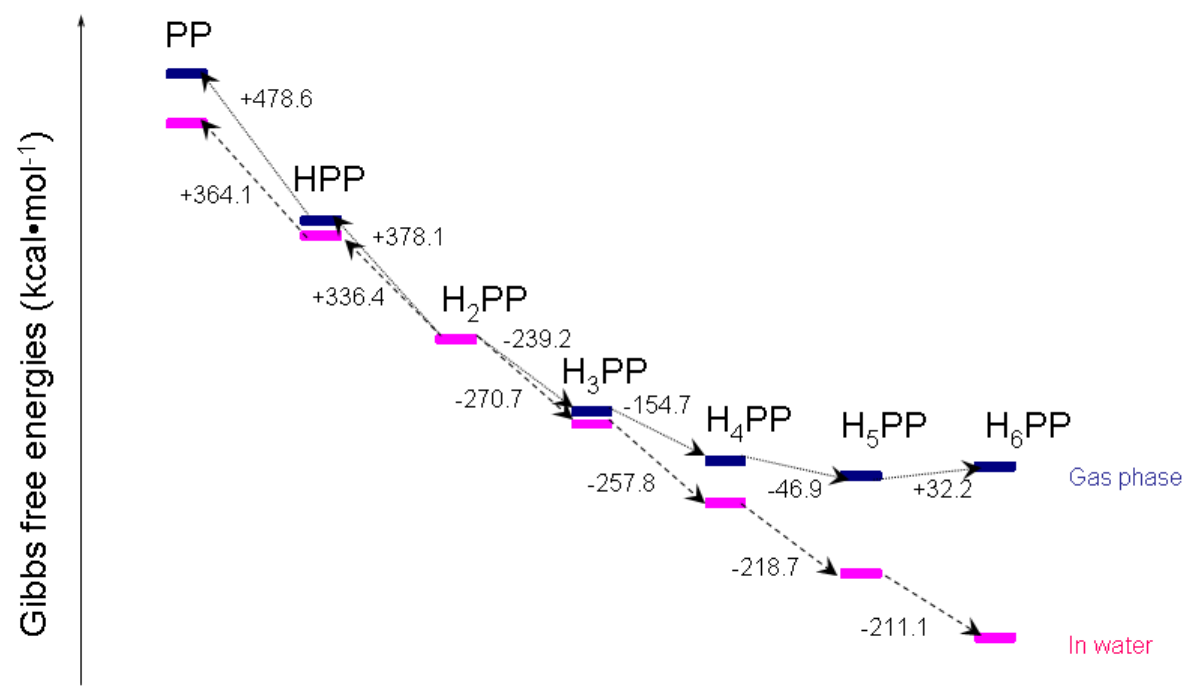




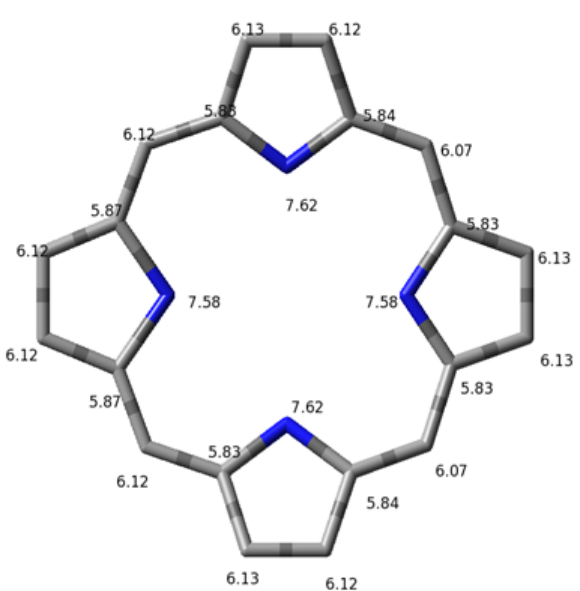

$\mathrm{H}_{5} \mathrm{PP}$

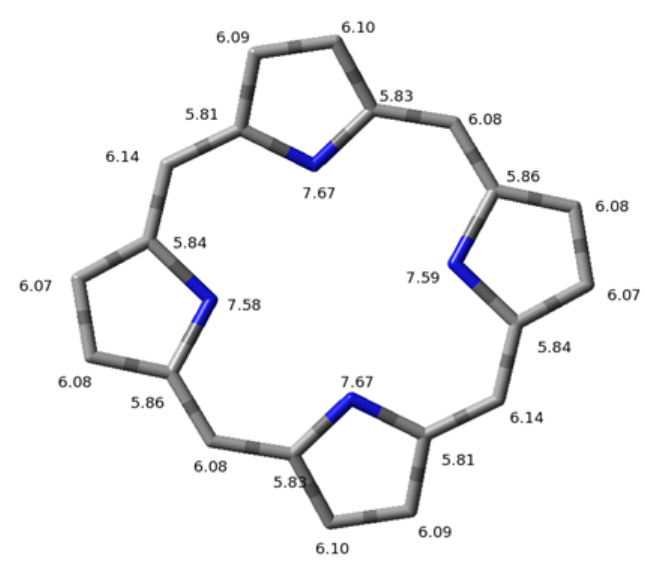

$\mathrm{H}_{6} \mathrm{PP}$ 


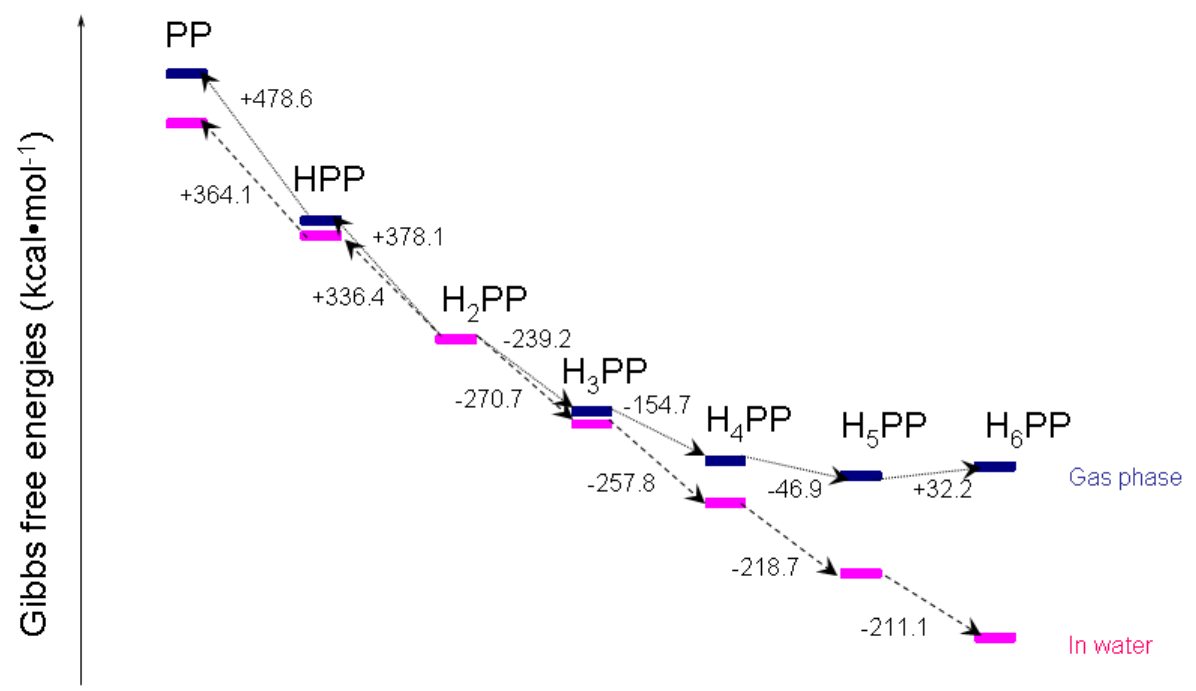

